\title{
METHODS OF USING IMMERSION TEACHING MODERN GREEK LANGUAGE IN A HIGHER EDUCATION
}

\author{
Natalya Voyevutko \\ Mariupol State University, Mariupol, Ukraine \\ nvoevoutko@yandex.ru \\ Olena Kuligina \\ Mariupol Municipal Technological Lyceum, Mariupol, Ukraine \\ kuligina.elena@mail.ru
}

\begin{abstract}
Immersion as a special bilingual teaching method is intended to plunge students into the learning environment by the way of transforming the teaching process into a language environment. Learning the Modern Greek language at the Mariupol State University in the process of training the Modern Greek-Ukrainian translators based on immersion methods emerges the actual methodological problem which can be solved by revitalizing the method of teaching some special subjects. The method of immersion teaching the Modern Greek language at the Higher Educational Establishment has been highlighted in the paper based on the special course of subjects under the title "Annotating and Abstracting Texts (Modern Greek language)" of the optional course for students obtaining the Master's degree. The special course mentioned above has been worked out on the basis of integrity and immersion. Teaching annotating and abstracting in the Modern Greek language accompanied with the methodology support as well as the syllabus and the reference book of clichés ensures the appliances named "Annotating and Abstracting Texts (Modern Greek language)". The considered work is provided with practical tasks presented in the form of texts of annotations and abstracts, scientific articles, dedicated to the issues of highlighting the actual issues of philology, linguistics, linguodidactics, comparative pedagogics and translation. As the subject is focused on teaching philologists and translators, immersion has some peculiarities. Firstly, it is multilingual as the teaching material is provided in three languages (Modern Greek, Ukrainian and English). Secondly, it is translation-oriented as immersion is realized not only in one main language (here it is the Modern Greek) but into the processes of Modern Greek - Ukrainian and English-Ukrainian translation. The method of using the immersive teaching in the special course is realized in the systematic use of the following principles: 1) harmonization of the learning language and the themes and contents of the language material; 2) gradual increasing of the complexity level of the tasks during the teaching process; 3) gradual increasing in number of the teaching materials in the Modern Greek language. The partial immersion in the course is being gradually changed by the full immersion.
\end{abstract}

Keywords: Modern Greek language; annotating and abstracting; immersion; immersive teaching.

Introduction. Content-based language teaching is an approach to second language instruction that involves the use of a second language to learn or practice content. In most instances, content is defined as material that is generally outside the realm of the traditional course material of language programmes. As such, many content-based courses or programmes use the second language as the medium for learning the content of specific courses (such as mathematics, science, art, or social sciences), shifting the focus from language as course content to language as the medium of instruction (Met, 1998, p. 35).

At the up-to-date stage of the development of native higher education training of foreign language philologists including specialists in the Modern Greek language needs definite revitalizing and improvement. It concerns not only highly qualified pedagogical support but a methodological support as well. Methods of teaching profession-oriented disciplines in a foreign language and working out special courses of optional type are of great importance nowadays. Just under these circumstances, the high quality of both professional and linguistic training is provided. Striving to improve the professional training of students-philologists ensures the actual role of immersion methods and a foreign language teaching approaches.

The term "immersion" derives from Latin "immersio" meaning "submerging or plunging". As of today, immersion is applied and researched in such areas as optics, maths, engineering, medicine, study of art, pedagogics, etc.

The term "immersion" was implemented in pedagogical process as a foreign language teaching method using a foreign language as a target language by Canadian School of Science and Pedagogics. 
Immersion in the sphere of lingua-didactics on the side of language contacts was researched by V. M. Pankin, A. V. Philipov. Immersion methods applied to learning foreign languages at schools of the U.S.A. and Europe were analyzed by A. V. Buzovskiy. The peculiarities of teaching foreign languages on the principles of immersion in the higher education in Europe were highlighted in research works of N. I. Zakordonets, whilst some aspects of implementing such an approach in Ukrainian higher education establishments were revealed by S. M. Sytnyakyvskyi.

Researchers studied the use of immersion both as a foreign language teaching method applied by M. Snow and a bilingual teaching method (J. Cenoz, Frd. Genesee, R. Lyster, D. P. Dolson, N. I. Zakordonets, S. M. Sytnyakyvska).

So, researchers studied the nature and sources of such a language phenomenon having tried to define the importance of immersion among teaching methods. However, the issue of immersive teaching of the Modern Greek language in national institutions of higher education hasn 't been the key subject of a special research yet.

It should be mentioned that the implementing process of immersion teaching in the certain higher education establishment within the definite specializations or disciplines may differ a lot. Under the following circumstances the necessity of working out the special courses and methods emerges. Thus, learning the Modern Greek language at the Mariupol State University while training translators from the Modern Greek language into the Ukrainian language on the basis of immersion occurs the actual methodological problem which can be solved by revitalizing the method of teaching some special subjects and academic disciplines.

The research aims to highlight the use of immersive teaching in the special course for students of the University under the title "Annotating and Abstracting Texts (Modern Greek language)" based on the immersive principles.

The objectives of the research may be achieved by realizing the following tasks:

- $\quad$ to define the essence of immersion teaching as a teaching method;

- to determine some peculiarities of teaching a foreign language on the principles of immersion in the higher education establishments;

- to analyze the immersion method in organizing the special course "Annotating and Referring of texts (Modern Greek language)".

\section{The essence of the immersion as a teaching method.}

V. M. Pankin, A. V. Philipov mention that the Canadian School of Science and Pedagogics defines the term of immersion as long plunging students into foreign language environment excluding or insignificant usage of mother language (Pan'kin \& Filippov, 2011).

Content-based language teaching is an approach to second language instruction that involves the use of a second language to learn or practice content. In most instances, content is defined as material that is generally outside the realm of the traditional course material of language programmes. As such, many content-based courses or programmes use the second language as the medium for learning the content of specific courses (such as mathematics, science, art, or social sciences), shifting the focus from language as course content to language as the medium of instruction (Cenoz \& Genesee, 1998, p. 35.)

Learning language through content provides students with opportunities to use language as it functions in the real world: to communicate authentic meanings, for authentic purposes, and to accomplish authentic tasks. (Cenoz \& Genesee,1998, p. 36)

M. Snow presented 10 core instructional strategies in effective immersion pedagogy. Several served primarily to assist comprehension: extensive use of body language, realia, visuals, and manipulatives, in addition to predictability in routines and redundancy in lessons (Snow, 1987, p. 65).

R. Lyster shares these views: language immersion has generally been defined as a programme in which the second language is not learned through language instruction but more exact sciences such as biology and geography taught in the second language. Key questions in immersion pedagogy are concerned with the ways in which and the extent to which analytic teaching strategies may be combined with more experiential ones in order to provide optimal conditions for second language learning (Lyster, 1998, p. 64). 
Frd. Genesee considers that immersion education is a type of bilingual education in which a second language (or second languages) is used along with the students' first language for curriculum instruction during some part of the students' elementary and/ or secondary schooling (Genesee, 1984, p. 32). In immersion programs, the same curriculum material is never taught in the child's native language and the second language during the same academic year.

Thus, the concurrent method of instruction that is practiced in some American bilingual education programs for minority language children precludes these programs from being considered immersion.

The major goals of immersion programs are:

1. To provide the participating students with functional competence in the second language.

2. To promote and maintain normal levels of first language development.

3. To ensure achievement in academic subjects commensurate with the students' academic ability and grade level.

4. To instill in the students an understanding and appreciation for the target language group and their language and culture without detracting in any way from the students' identity with and appreciation for the home language and culture. (F. Genesee,1984, p. 32).

D. Dolson summarises that immersive education is an organized curriculum designed to provide second language instruction to majority language students at no cost to their academic achievement and native language development.

The educational researchers began to describe this type of practice more carefully, "sink or swim" learning environments became known as submersion. Submersion programs are defined as a curriculum designed for native speakers of a language, but often used inappropriately with language minority students (Dolson,1984, p. 5).

The scientific literature also offers another characteristics of immersion. For instance, as a variant of a bilingual education when students speak the language of the greater part of population and partly learn by means of the second or the first language. It provides an opportunity to define different modifications of immersion like "early", "late", "total" and "partial" (Pan'kin \& Filippov, 2011).

S. M. Sytnyakivska points out that "early" immersion presupposes learning all the subjects in a foreign language from the first year of learning, learning while keeping communication in mother language out of class time. "Late" immersion means that the second language is learnt as a foreign one. "Total" or "full" immersion means the study of all academic subjects in a foreign language. "Partial" immersion limits the number of subjects studied in a foreign language (Sytnyakivs'ka, 2013).

A. V. Buzovsky thinks that in European schools, where immersion is considered as a special method of bilingual teaching, it is " the most successful example" of teaching a foreign language as it enables students to achieve a high level of knowledge and students are guaranteed profound mastering of contents of definite disciplines taught in foreign languages (Buzovs'kyy, 2011).

Thus, immersion is a method of teaching foreign languages which means the transformation of the teaching process into a language environment. This principle works both for learning one foreign language and bilingual teaching.

\section{Foreign language Immersive teaching at a higher educational institution.}

N. I. Zakordonets in the course of researching immersive concepts of bilingual learning of professional disciplines in the leading European countries makes an accent on the importance of the contents of "immersion" act providing a necessary base of terms and notions ensuring efficient profession-oriented communication in a foreign language. The researcher also points out the importance of a thorough selection and didactic arrangement of the text materials regarding contents of professional disciplines (Zakordonets', 2013).

For students of nonlinguistic professions who study professional disciplines in a foreign language S. M. Sytnyakivska suggests presenting lectures in a bilingual way using the method of "variative approaches" as a kind of immersion. The essence of the method is as follows: the teacher when presenting a lecture gradually increases the amount of lexical material in a foreign language until he/she reaches the critical point where students don't understand material presented in a foreign 
language, then the teacher (keeping to interactive mode of contact with the audience) returns to explaining of phenomena in the mother language (Sytnyakivs'ka, 2013).

We are likely to incline to the opinion of N. I. Zakordonets who has declared that one of the most important conditions of organizing a bilingual teaching in the national higher educational institutions is the integrity of the teaching process on two levels of its realization - the inner level of the subject "Foreign Language" and the interdisciplinary level of a foreign language as a didactic synthesis of foreign languages and professional subjects considering such important aspects of students' training as contents of academic subjects, activity, organization and methods while securing the autonomous status of integrated disciplines (Zakordonets', 2013).

Thus, for the purpose of a higher efficiency of teaching the special course of annotating and referring of texts has been worked out basing upon the grounds of integrity and immersive character.

\section{Using immersive method in the special course "Annotating and Abstracting of texts (Modern Greek language)".}

3.1. Description of the special course. The special course "Annotating and Abstracting of texts (Modern Greek language)" (Voyevutko, 2014) relates to the cycle of optional disciplines and was worked out for students of educational level of "Master" of the first year for professional training course "Modern Greek Translation Studies)", Specialization "Translation (Modern Greek language)", Specialization "Language and Literature (Modern Greek language)". A number of credits for mastering the special course is 6:3 per each term in an academic year. The ratio of academic hours in class to individual ones is 88/128, which are distributed as follows: 40 hours of lectures, 48 hours of seminars and practice, 96 hours of self-study activity, 32 hours for individual classes.

The aim of the special course is teaching annotating/abstracting texts using immersive principles to provide a complex training of specialists.

The development of skills necessary for annotating/abstracting texts is achieved through solving the following tasks:

- Improving the skills of analysis of the structure and lexical architectonics of a text in general and on the level of microstructures;

- Training for annotating and abstracting of oral and written profession-oriented texts in Modern Greek;

- Teaching the basics of edition of annotated text of translation in accordance with norms of the Ukrainian language;

- Training correct arranging of an annotated/ abstracted text with the help of a computer text editor software.

As the result of studying the academic discipline a student should know the peculiarities of development of abstracting processes in Ukraine; peculiarities of formation of the National abstracting system; terms, notions and functions of annotations and abstracts; stages of the process of abstracting and annotating; common features and differences of theory and practice of arranging annotations /abstracts in Ukraine and Modern Greek-speaking countries.

A student should be capable to arrange annotations/abstracts of various types of oral and written texts considering their communicative functions, functional styles etc. (communicative competence); differentiate markers of language characteristics of people (social status, ethnic group, etc.) on all language levels (sociolinguistic competence); use the rules of adequately in both Ukrainian and Modern Greek to achieve coherent and consistent base upon composition and speech forms (pragmatic competence); master skills of abstracting original pronunciation despite of the peculiarities of the source (live voice, audio/video records, etc. ); master skills of scientific text processing (translator's annotation/abstracting); be able to carry out creative tasks stimulating progress in language and special training in their continuous relationship.

Contents of lectures, seminars and practical classes creates both informative and practical basis for students aimed to transform knowledge into skills which in its turn grants professional competence of the future specialist. Individual skills and competence are perfected in the process of autonomous activity of students. 
Besides, the credit module system of organization of teaching in a higher educational institution includes individual scientific research tasks (ISRT) in the special course "Annotation and Abstracting of Texts (Modern Greek language)".

The aim of the ISRT is an improvement of skills of annotated/abstracted translation and the further development of research skills of students.

In accordance with the aim the following tasks have been distinguished, that is: to teach students arranging reference materials on appointed themes with elements of scientific research; to teach annotating sources which have been processed including audio/video files, presentations, etc.; to expand both active and passive Modern Greek vocabulary according to the themes approximately to 900 units; to make students acquainted with political culture, history and traditions of The Republic of Greece and The Republic of Cyprus.

\subsection{Immersion in the special course.}

3.2.1. Auditory lessons. Immersion in auditory lessons is partial. The contents of auditory lessons has been coordinated with requirements for students' knowledge and skills mentioned above. Lectures are delivered both in Modern Greek and Ukrainian languages.

The choice of the language of teaching (questioning, conversations, discussions, answers etc.) depends upon the exact objectives and tasks of every separate lesson. For example, the information about the development of abstracts system in Ukraine and formation of the National system of abstracting is preferable to be given in the Ukrainian language. At the same time, information about peculiarities of terms and notions in Greek education and science is provided in Modern Greek from authentic sources.

Seminars in the special course aim to enable students to practice their skills in annotating and abstracting in Ukrainian and Modern Greek as well as translating and editing the text of a translation. That's why the choice of teaching language depends on the text which is to be annotated.

A full immersion into Modern Greek language and translation process is conducted gradually. To realize such immersion a special attention is paid to a thorough selection of textual materials and arranging tasks to it as well as organization of seminars and practical lessons. Firstly, the contents of analyzed authentic texts includes information which expands professional knowledge. Secondly, tasks for profession-oriented texts are grouped in accordance with the principle of gradual sophistication. Thirdly, the character of tasks changes from illustrative and reproductive to constructive and creative ones. Fourthly, the number of tasks in Modern Greek is being increased to maximum.

Thus, the author of the article provides the syllabus "Annotating and Abstracting Texts (Modern Greek language)" accompanied with curriculum and the reference book of clichés ensures the methodological support. The material for exercises and tasks is presented as texts of annotations and abstracts, scientific articles dedicated to the issues of highlighting the actual problems of philology, linguistics, linguodidactics, comparative pedagogics and translation. The exercises have been distributed among separate modules:

1. "Preparation exercises (Ukrainian and Modern Greek languages)", for example, find a word or a quotation in the given paragraph which can be used as the heading for the text; generalize the information making one sentence of several provided; distinguish keywords in the texts provided; find the main and additional information in the text; make up a plan of the text; summarize the text; retell the text up to the topic.

2. "Language means of annotation (Modern Greek)". For instance, "look through the given annotations and analyze the stylistic genre-forming role of the idioms in italics, write out language clichés and translate them; read the provided texts and write out phrases typical for for the genre of annotation, translate them; match synonyms of various styles; make a Modern GreekUkrainian glossary of language means of annotations, add synonymic constructions to the glossary".

3. "Translation of annotations (Modern Greek, English, Ukrainian)", e.g. "translate the annotations (variants of the above-mentioned languages); make several possible variants of translation with the help of the glossary". 
4. "Annotation (Modern Greek, Ukrainian languages)", for example, "make an annotation in the chosen language to the theses of a scientific article; make annotations of the scientific article in the chosen languages".

5. "Editing annotations (Modern Greek and Ukrainian languages)", for example, "read the article and the annotation to it paying attention to the contents, grammatical arrangement, stylistic and genre correspondence, edit the annotation keeping up to the lexical accuracy (lexical compatibility, linguistic redundancy, use of synonyms, antonyms, polysemantic words, homonyms, paronyms; make an editing of the annotation to the article paying attention to the stylistic colouring of the article (use of estimating vocabulary, terms, clichés).

6. "Thematic statements (Modern Greek, Ukrainian)", for example, "make thematic statements from the provided article to define a certain notion, translate it into a chosen language; edit (remove unnecessary elements, make stylistic and grammatical editing, add elements) the thematic statements in a chosen language; make a peer-reviewed translation".

7. "Creative tasks (Modern Greek, Ukrainian)", e.g. "make an annotation (in Ukrainian)

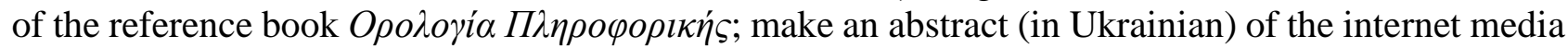

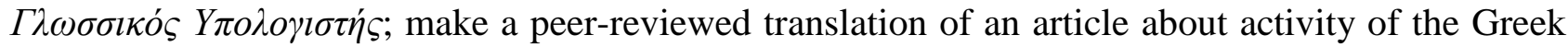

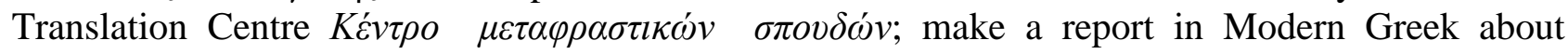
international activity of Mariupol State University, etc.

3.2.2. Immersion at individual scientific research tasks. During studying the discipline "Annotation and abstracting of texts" students have to carry out two ISRTs - one per semester.

Examples of tasks:

1. Make an analytical/informative report/ review on the problems of up-to-date (social, economic, humanitarian) politics of The Republic of Greece and The Republic of Cyprus.

2. Make a reference/ review of the most important draft laws which regulate the (social) spheres of The Republic of Greece and The Republic of Cyprus.

3. Generalize theoretical and practical experience of The Republic of Greece and The Republic of Cyprus connected with legislative support of transformation processes in the sphere of education.

In the process of carrying out ISRTs, a full immersion takes place as students use Modern Greek to process the materials and arrange reports. The defence of the study project is conducted in Modern Greek in the form of presentation of reports or abstracts accompanied with sources of information and is estimated up to the following general criteria: individual work; logic and sequence within presenting the information; disclosure of the theme; the amount and variety of reference materials used; quality design of reports.

Thus, one can see that in the process of studying the special course "Annotation and abstracting texts (Modern Greek language)" the immersion teaching method accompanied with gradual increasing of complexity and the size of texts in Modern Greek Language classes is used. It provides lectures, seminars and practical classes, annotating and abstracting literature, work with the Internet sources. In this process creative editing tasks such as abstracting, analogues, testing hypotheses, abstract thinking, objective analysis, transformations, research, trial and error method based on the method of Z. V. Partyko play an important role.

Conclusions. Immersion as a method of teaching foreign languages means the transformation of the teaching process into the language environment. The special course "Annotation and Abstracting texts (Modern Greek language)" has been worked out on the base of immersive principles and the grounds of integrity for students of Higher Educational Institutions of a"Master's" level qualification. This academic discipline is oriented to the training of philologists and translators and it forms some specific features of immersion. Firstly, it's the use of many languages as the material is provided in three languages (Modern Greek, English and Ukrainian). Secondly, its orientation on translation process presupposes immersion not only into the Modern Greek language but into the processes of Modern Greek-Ukrainian and English-Ukrainian translation. The method of using immersive teaching in the special course systematically follows such principles as:

1) harmonization of the language of teaching with the language, themes and the content of the teaching material; 
2) the gradual increase of the level of complexity of the tasks during the teaching period;

3) the gradual increase of teaching materials amount in the Modern Greek language.

Within the course partial immersion gradually transforms into full immersion.

Further research will be focused on researching methods and organization of immersive teaching the Modern Greek language in European countries.

\section{References:}

Dolson, D. (1984) Introduction for Studies on Immersion Education. A Collection for United States Educators Prepared under the direction of the Office of Bilingual Bicultural Education. California: California State Department of Education.

Genesee, F. (1984) Historical and Theoretical Foundations of Immersion Education. In California State Department of Education (Eds.) Studies on Immersion Education. A Collection for United States Educators Prepared under the direction of the Office of Bilingual Bicultural Education: California State Department of Education (pp. 32-57). California: California State Department of Education.

Lyster, R. (1998) Immersion pedagogy and implications for language teaching. In J. Cenoz and F. Genesee (eds.), Beyond Bilingualism: Multilingualism and Multilingual Education (pp. 64-95). Clevedon, UK: Multilingual Matters.

Met, M. (1998) Curriculum decision-making in content-based language teaching. In J. Cenoz \& F. Genesee (eds.). Beyond Bilingualism: multilingualism and multilingual education (pp. 35-63). Philadelphia: Multilingual Matters.

Snow, M. (1987) Immersion Teacher Handbook (Educational Report ER10). Los Angeles, CA: University of California Center for Language Education and Research. (ERIC Document Reproduction Service No. ED 291243).

Buzovs'kyy, A. V. (2011) Dvomovna osvita u shkolakh SSHA ta Yevropy [Bilingual education in schools in the US and Europe]. Naukovyy visnyk Donbasu, 2.

Pan'kin, V. M., \& Filippov A.V. (2011) Yazykovyye kontakty: kratkiy slovar' [Language contacts: Concise Dictionary] Retrieved from http://www.kniga.com/books/preview txt.asp?sku=ebooks319531

Sytnyakivs'ka, S. M. (2013) Deyaki aspekty vprovadzhennya aktyvnykh metodiv bilinhval'noho navchannya pry pidhotovtsi mahistriv iz sotsial'noyi pedahohiky [Some aspects of the implementation of active methods of bilingual education in the preparation of the Master of Social Pedagogy]. Zbirnyk naukovykh prats' Natsional'noyi akademiyi Derzhavnoyi prykordonnoyi sluzhby Ukrayiny im. B. Khmel'nyts'koho, 1(66), 257-269.

Voyevutko, N. Yu. (2014) Anotuvannya ta referuvannya tekstiv novohrets'koyu movoyu: Navchal'nyy posibnyk-dovidnyk. [Annotation and Modern Greek language text abstracting: Manual Directory]. Mariupol', Ukraine.

Zakordonets', N. I. (2013) Realizatsiya kontseptsii dvomovnoho navchannya v protsesi vyvchennya profesiynykh dystsyplin u providnykh krayinakh Yevropy [Concept implementation bilingual education in the study of professional disciplines in the leading European countries]. Naukovi zapysky Ternopil's'koho natsional'noho pedahohichnoho universytetu imeni Volodymyra Hnatyuka. Seriya: pedahohika, 1, 108-111. 